\section{LL-04 ADVOCACY MATTERS CREATIVELY SPREADING LUPUS AWARENESS AND EDUCATION}

'Deidre Gee Baptista*, ${ }^{2}$ Kirsten Gee Maeda. ${ }^{1}$ Rocklin, CA. USA; ${ }^{2}$ Irvine, CA. USA. 'The GEE Twins for Lupus', University of California, Irvine

10.1136/lupus-2018-Ism.114

Background 'The Gee Twins for Lupus' Butterfly pin project served as a way to spread lupus knowledge through grassroots advocacy efforts. This project's goal was to further awareness, education and advocacy, providing hope and optimism. Over 1000 handcrafted awareness pins were created and shared with lupus communities. The goal was to design a visually meaningful May awareness pin that represented hope for patients, sisters' synergy and awareness for racial disparities. 'Asian/Pacific Islanders and Hispanics of any race are more likely to be affected by the autoimmune disease lupus, compared with Whites (regardless of Hispanic ethnicity).'

Methods Patient advocates participated in lupus events sharing their story and awareness pins at national, state, county, and local levels. Advocacy helps to ensure that the whole patient is supported. Gaining resilience, optimism, and coping strategies; patients can become empowered when getting involved in lupus communities.

The handcrafted butterfly pins designed purposefully in Chinese brocade fabric in (orange and purple) chosen to bridge lupus communities together to symbolize hope. The pins have evoked engaging lupus conversations from racial disparities, treatments to the importance of nutrition, and exercise while providing hope and optimism. The pin project has symbolized the sister's grassroot advocacy work by raising awareness wherever they go.

Results Using collaborative patient advocate voices and a creative project, Lupus awareness and education increased. 'The Gee Twins for Lupus' efforts resulted in speaking engagements, featured in newspaper articles, and on social media platforms generated awareness. Advocates became a resource for patients connecting them to lupus organizations. Advocacy work and patient engagement resulted in grants, large donor contributions, permanent outdoor butterfly tile mural/garden, increased education for racial disparities and collaborative projects. Refer to figure 1 for project results. Creative patient advocates utilized their creative talents to expand the voice and reach of lupus awareness.

Conclusion Advocating matters. Utilizing creative twin synergy has elevated awareness. Featured articles and social media has spread awareness. For example, University of California Irvine's 2018 Winter magazine, was sent to UC Irvine's community. The project is an example of how impactful advocacy can be. Continued projects include: working with lupus warriors, researchers, industry leaders helping to solve the complexity of lupus. Aiding racial disparity needs more grassroot voices and hoping to further global reach. It is through compassion and love that awareness was spread as brave patients are inspirational.

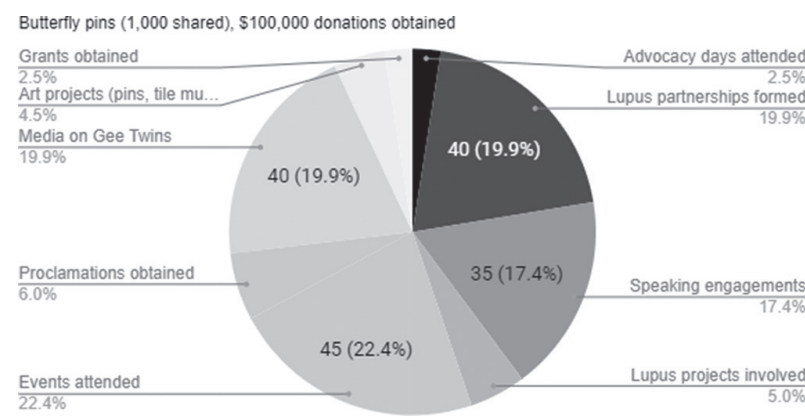

Abstract LL-04 Figure 1 Accumulation of advocacy (the gee twins for lupus)

\section{REFERENCE}

1. Lupus Impacts Asian/Pacific Islanders and Hispanics at Alarming Rates. (2017, September 11). Retrieved from https://www.lupus.org/research-news/entry/lupusimpacts-asian-pacific-islanders-and-hispanics-at-alarming-rates

Acknowledgements The authors would like to thank, The Lupus Foundation of Northern California (LFNC), Lupus research Alliance (LRA), Lupus LA, Cities of Irvine, Rocklin, Orange and Placer Counties, University California Irvine, The Baptista, Gee, and Maeda families and to the many supportive lupus patients, generous donors and nonprofits across the U.S. that have supported and inspired them over the years.

\section{LL-05 FABULUPUS: A SOCIAL MEDIA EVALUATION}

${ }^{1} J o d i e$ Nimigon-Young*, ${ }^{2}$ Jessica Kundapur. 'Ottawa Hospital, Ottawa, Ontario, Canada; ${ }^{2}$ Kundapur Clinical Consulting, Nijmegen, The Netherlands

\subsection{6/lupus-2018-Ism.115}

Background Fabulupus is the only book for young adults, written by young adults with lupus. It was published in December 2012 and addresses all areas of lifestyle for an individual with this chronic illness.

Methods Qualitative analysis of Facebook and Instagram accounts associated with Fabulupus. Entries were assessed based on number of comments and/or acknowledgements.

Results The most popular items include sleep and work balance.

Conclusions Young adult lupus patients are most interested in seeking additional resources and information concerning daily life struggles of living with a chronic condition. Social media posts concerning medical information tend to not draw as much attention. We urge researchers to consider these topics as crucial for further investigation, as well as clinicians to have open conversations with their patients on their general coping. For future, it would be of interest to compare with other like-minded social media for young adults with lupus. 